\title{
QUALIDADE BACTERIOLÓGICA DE AMOSTRAS DE ÁGUA EM ESCOLAS PÚBLICAS DO MUNICÍPIO DE TANGARÁ DA SERRA, MATO GROSSO
}

\author{
M. J. VIANA, H. M. L. SOUZA, I. F. CARVALHO*, M. L. S. CARVALHO \\ Universidade do Estado de Mato Grosso (UNEMAT), Campus de Tangará da Serra. \\ iliocarv@gmail.com*
}

Submetido 30/09/2016 - Aceito 13/11/2018

DOI: $10.15628 /$ holos.2018.5124

\section{RESUMO}

A água potável corresponde a toda água disponível na natureza e que não oferece riscos para os seres vivos que a consomem. Embora existam diversos fatores importantes que determinam a potabilidade da água, a ausência de bactérias do grupo coliforme é um dos principais parâmetros que devem ser avaliados. Desta forma, monitorar a qualidade da água dentro do ambiente escolar, local em que os estudantes passam grande parte do seu tempo, torna-se necessário para garantir que os mesmos tenham acesso a água de qualidade. Diante deste contexto, esta pesquisa teve como objetivo avaliar a qualidade bacteriológica de amostras de água de escolas públicas do município de Tangará da Serra, Mato Grosso. Foram realizadas duas coletadas de amostras em 14 escolas e o método utilizado para detecção de coliformes totais e Escherichia coli foi o uso do Kit "Colitag ${ }^{\mathrm{TM}}$ ". Os resultados revelaram que não houve amostras positivas para $E$. coli, no entanto, $21.4 \%$ das amostras apresentaram confirmação da presença de coliformes totais, não atendendo os parâmetros exigidos pela portaria $n^{\circ} 2.914 / 2011$ do Ministério da Saúde. Vale ressaltar que a contaminação por bactérias do grupo coliformes totais é fator preocupante, uma vez que estas podem indicar a existência de enterobactérias na água. Entre as escolas avaliadas, uma escola (E2) apresentou coliformes totais nas duas coletas. Os resultados deixam evidente que em algumas escolas, há necessidade de maior vigilância da qualidade da água e identificação dos fatores locais que podem estar ligados a contaminação encontrada.

PALAVRAS-CHAVE: Coliformes Totais, Coliformes Termotolerantes, escola, potabilidade.

\section{QUALITY BACTERIOLOGICAL OF WATER SAMPLES IN PUBLIC SCHOOLS OF THE CITY OF TANGARA DA SERRA, MATO GROSSO}

\begin{abstract}
Drinking water corresponds to all water available in nature and does not pose risks to living beings who consume it. Although there are several important factors that determine the potability of water, the absence of bacteria of the coliform group is one of the main parameters that must be evaluated. In this way, monitoring water quality within the school environment, where students spend much of their time, becomes necessary to ensure that they have access to quality water. Given this context, this research aimed to evaluate the bacteriological quality of water samples from public schools in the Tangará da Serra, Mato Grosso municipality. There were collected two samples on 14 schools and the method used for the detection of total coliforms and Escherichia coli was the use Kit
\end{abstract}

KEYWORDS: Total coliforms, Thermotolerant coliforms, school, potability. 


\section{INTRODUÇÃO}

A água constitui atualmente uma das principais preocupações mundiais no que diz respeito aos seus usos e à sua manutenção como um bem de todos, em quantidade e qualidade adequadas (SÁ et al., 2005). No Brasil, o direito de consumir água de qualidade tem se estabelecido a partir do Decreto Federal no 79.367 de 9 de março de 1977 (FREITAS \& FREITAS, 2005). Desde então, o governo brasileiro tem elaborado novas legislações para garantir o controle e vigilância da qualidade da água para consumo humano e seu padrão de potabilidade, atualmente configurada através da Portaria no 2.914, de 12 de dezembro de 2011.

A água potável corresponde a toda água disponível na natureza destinada ao consumo e possui características que não oferecem riscos para os seres vivos que a consomem, seguindo certos parâmetros físico-químicos e microbiológicos (CASTRO et al., 2013; BRASIL, 2014). Na maioria dos países em desenvolvimento, ainda há certa carência de saneamento básico, fato que expõe a população ao consumo de água não potável, ou seja, contaminada com microorganismos patogênicos causadores doenças ligadas à água (SPERLING, 2014).

O monitoramento das condições sanitárias de água para consumo é realizado principalmente através de análises das bactérias do grupo coliformes (coliformes totais e Escherichia coli) (ZAGO et al., 2013). Essas bactérias são comumente encontradas no trato intestinal de animais de sangue quente sendo, portanto, indicadores de poluição fecal (HOFSTRA \& VELD, 1988; FERNANDES et al., 2014; AMARAL, 2011). Os coliformes totais são caracterizados por fermentarem a lactose com a produção de gás a $35^{\circ} \mathrm{C}$ em $24-48 \mathrm{~h}$, enquanto os coliformes termotolerantes fermentam a lactose com a produção de gás a $44.5-45.5^{\circ} \mathrm{C}$, no período de $24 \mathrm{~h}$ (SILVA et al., 2010).

Uma tendência quanto aos métodos utilizados para detecção de coliformes totais e $E$. coli em amostras de água tem sido o emprego de métodos rápidos em substituição ao método convencional de fermentação em tubos múltiplos, principalmente porque são práticos, de menor custo, reduzem o tempo de análise e não necessitam de etapas confirmatórias (MARQUEZI, GALO \& DIAS, 2010; FERNANDES \& GOIS, 2015). Por utilizarem somente um meio de cultura e fornecer o resultado em 24 horas, torna-se possível a execução de ações corretivas, caso seja detectada a contaminação. A água contaminada por bactérias não apresenta drásticas alterações nas características físico-químicas como ocorre em águas poluídas, fato que demonstra a importância do uso desta técnica para detectar a presença de bactérias nocivas à saúde humana (MARQUEZI, GALO \& DIAS, 2010). Entre os métodos rápidos que foram aprovados pela Agência de Proteção Ambiental dos Estados Unidos (US-EPA), destacam-se Colilert ${ }^{\circledR}$, Colisure ${ }^{\circledR}$, Chromocult $^{\circledR}$, Coliscan $^{\circledR}$ e Colitag ${ }^{\mathrm{TM}}$, sendo que todos são baseados na detecção de enzimas que estão associadas com estas bactérias de interesse sanitário (OLSTADT et al., 2007).

A existência de ações de vigilância sanitária, tais como o controle da qualidade da água para consumo humano, são significativas, pois pode promover a garantia de saúde à população, no entanto, análises de controle de qualidade são realizadas mensalmente e em poucos pontos de amostragem por local e também podem ocorrer contaminações das caixas d'água e bebedouros das escolas. Neste sentido, investigações sobre a qualidade da água em instituições públicas, tais como escolas, são necessárias, pois os estudantes da educação básica passam 
grande parte do seu tempo na escola. Trindade et al., (2015) mencionam que a permanência dos estudantes na escola acaba determinando que seja ingerido relevantes quantidades de água pela comunidade escolar. Por isso, a água distribuída nos estabelecimentos escolares deve obrigatoriamente ter qualidade potável de acordo com o preconizado pela legislação vigente.

Assim, diante deste contexto e da importância do consumo de água potável pelos estudantes de escolas públicas, este trabalho objetivou avaliar a qualidade de amostras de água coletadas em diversas escolas públicas do município de Tangará da Serra do Estado de Mato Grosso (MT), utilizando um método rápido de análise microbiológica para detecção da contaminação por coliformes totais e E. coli.

\section{MATERIAL E MÉTODOS}

\subsection{Coleta de amostras}

Um total de 14 escolas públicas, pertencentes ao município de Tangará da Serra, região sudoeste de Mato Grosso (Figura 1), foram selecionadas para coleta de amostras de água (Tabela 1). A coleta das amostras foi efetuada em dois bebedouros de cada escola e em dois períodos distintos: uma coleta realizada no mês de dezembro de 2014 e a outra coleta em outubro de 2015, totalizando 56 amostras de água.

Os procedimentos para a coleta da água foram realizados conforme recomendações do Manual de análise da água da Fundação Nacional de Saúde (FUNASA) (Brasil, 2013). Inicialmente, as partes externas e internas das torneiras foram higienizadas através de um algodão embebecido em álcool 70\%. Em seguida, a torneira foi aberta deixando à água correr por 1 minuto. Logo após, $100 \mathrm{~mL}$ das amostras de água foram coletadas com frascos estéreis que foram lacrados e identificados. Todas amostras foram acondicionadas em caixas isotérmicas contendo gelo e encaminhadas para o Laboratório de Microbiologia do Centro de Pesquisas, Estudos e Desenvolvimento Agro-Ambiental (CPEDA) da Universidade do Estado de Mato Grosso (UNEMAT), do campus de Tangará da Serra.

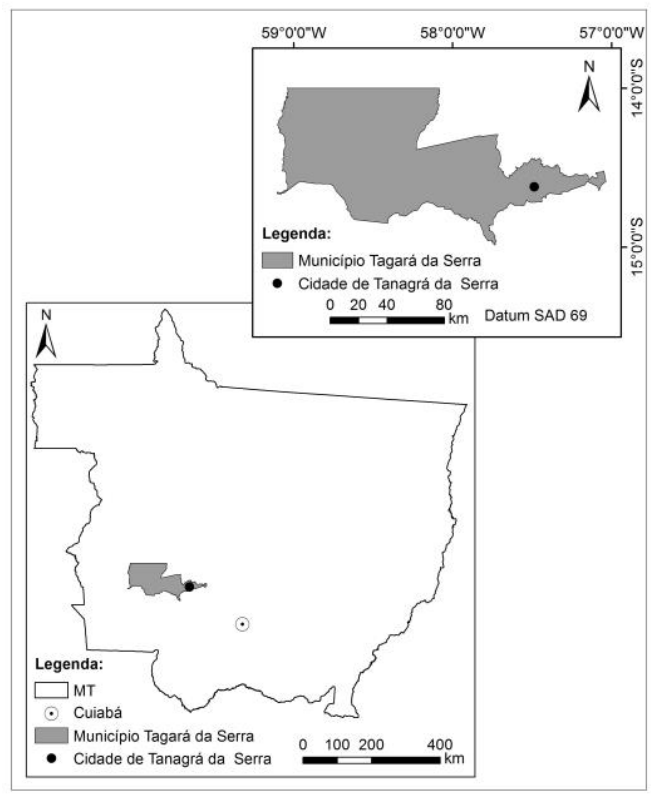

Figura 1: Localização do município de Tangará da Serra no Estado de Mato Grosso. 
Tabela 1: Local de coleta de amostras de água em escolas públicas do município de Tangará da Serra/MT.

\begin{tabular}{lc}
\hline Áreas & $\begin{array}{c}\text { Local da Coleta } \\
\text { (Código de identificação) }\end{array}$ \\
\hline Escola Urbana & E1 \\
Escola Urbana & E2 \\
Escola Urbana & E3 \\
Escola Urbana & E4 \\
Escola Urbana & E5 \\
Escola Urbana & E6 \\
Escola Urbana & E7 \\
Escola Urbana & E8 \\
Escola Urbana & E9 \\
Escola Urbana & E10 \\
Escola Urbana & E11 \\
Escola Urbana & E12 \\
Escola Rural & E13 \\
Escola Rural & E14 \\
\hline
\end{tabular}

\subsection{Uso do kit "Colitag ${ }^{\mathrm{TM}}$ "}

O método de análise para detecção da presença de coliformes totais e $E$. coli aplicado neste estudo foi o uso do Kit "Colitag'Тм", aprovado pela Agência de Proteção Ambiental dos Estados Unidos (US-EPA). Colitag ${ }^{\mathrm{TM}}$ usa o substrato incolor orto-nitrofenil- $\beta$-D-galactopiranósido (ONPG) para detectar coliformes totais que sintetizam a enzima $\beta$-D-galactosidase, responsável por clivar o substrato e produzir uma mudança na respectiva coloração (amarelo). O substrato 4metil-umbeliferil- $\beta$-D-glucuronídeo (MUG) está presente para deteç̧ão de $E$. coli, produtora da enzima $\beta$-glucoronidase que cliva o substrato fluorogênico, produzindo coloração azulada que se observa sob o comprimento de onda ultravioleta (366 nm) (USEPA, 2004).

As amostras obtidas foram inicialmente desinfetadas externamente com álcool 70\% e em seguida adicionado-se a solução de Hach Modificado Colitag ${ }^{\mathrm{TM}}$. Os frascos foram homogeneizados e as amostras foram incubadas por $16-22$ horas a $35^{\circ} \mathrm{C} \pm 0,5^{\circ} \mathrm{C}$. Após incubação foi verificado a coloração das amostras. Conforme mencionado anteriormente, a coloração amarela indicou a presença de coliformes totais. Os frascos positivos para coliformes totais foram submetidos sob luz ultravioleta para confirmação da presença de $E$. coli. Os frascos incolores indicaram ausência de coliformes. $O$ uso de estatística descritiva foi empregado para demonstrar o quantitativo de escolas que atenderam a Portaria n. 2.914/2011 do Ministério da Saúde quanto a potabilidade de água ingeridas pelos estudantes.

\section{RESULTADOS E DISCUSSÃO}

Os resultados das análises indicaram a presença de coliformes totais em algumas escolas, mas todas amostras das 14 escolas demonstraram ausência de coliformes termotolerantes. Na primeira coleta, os resultados foram positivos para coliformes totais foram obtidos na escola urbana E2 e a escola rural E13. Na segunda coleta, somente as escolas urbanas E2, E6 e E9 apresentaram alterações na qualidade da água. Observa-se que a escola E2 apresentou alteração na qualidade da água nas duas coletas que foram realizadas (Tabela 2). 
Tabela 2 - Resultados das análises microbiológicas da água consumida em escolas do município de Tangará da Serra/MT, no período de dezembro de 2014 (1a coleta) a outubro de 2015 (2a coleta). Legenda: "A" indicam ausência e letras " $\mathrm{P}$ " indicam presença.

\begin{tabular}{ccccc}
\hline \multirow{2}{*}{ Local da Coleta } & \multicolumn{2}{c}{ 1- coleta } & \multicolumn{2}{c}{ 2a coleta } \\
\cline { 2 - 5 } & $\begin{array}{c}\text { Coliformes } \\
\text { Totais }\end{array}$ & E. coli & $\begin{array}{c}\text { Coliformes } \\
\text { Totais }\end{array}$ & E. coli \\
& A & A & A & A \\
E1 & P & A & P & A \\
E3 & A & A & A & A \\
E4 & A & A & A & A \\
E5 & A & A & A & A \\
E6 & A & A & P & A \\
E7 & A & A & A & A \\
E8 & A & A & A & A \\
E9 & A & A & P & A \\
E10 & A & A & A & A \\
E11 & A & A & A & A \\
E12 & A & A & A & A \\
E13 & P & A & A & A \\
E14 & A & A & A & A \\
\hline
\end{tabular}

Os resultados oriundos da 1a coleta demonstraram que um total de $14.3 \%$ das amostras das escolas apresentou a presença de coliformes totais. Após a 2a coleta, este resultado aumentou para $21.4 \%$ (Figura 1), fato que revela a necessidade de maior frequência de inspeções sobre a qualidade da água consumida pelos estudantes, principalmente na escola E2 que apresentou resultado positivo nas duas épocas de amostragem, assim como nas escolas E6, E9 e E13, que apresentaram resultado positivo em pelo menos uma das coletas.

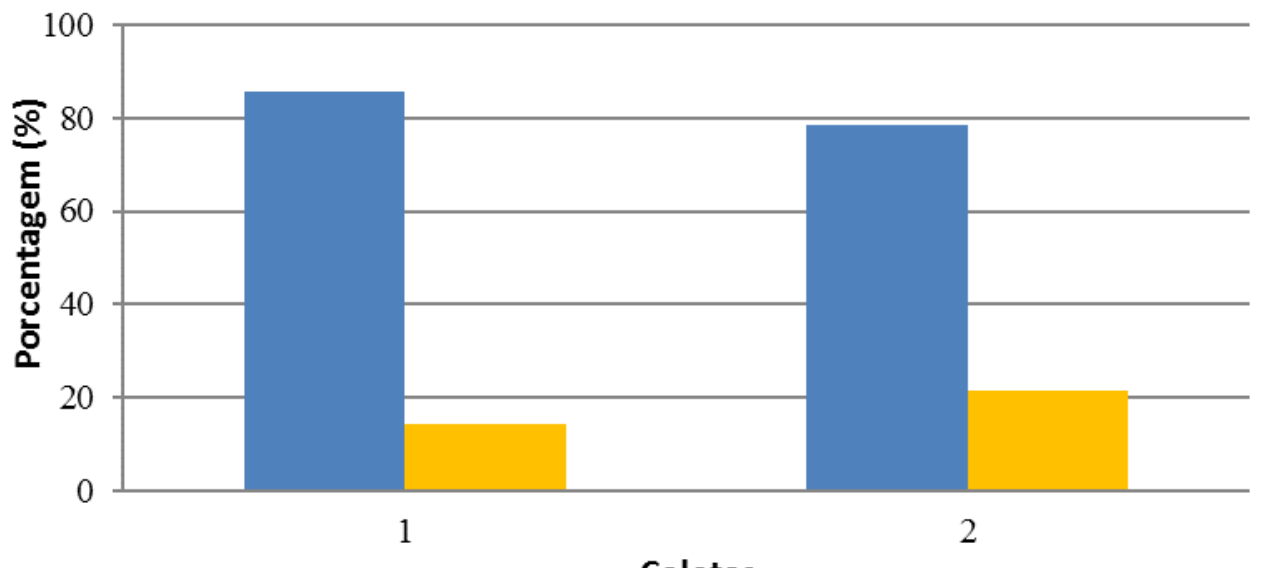

Coletas

Escolas que atenderam legislação — Escolas que não atenderam a legislação

Figura 1: Porcentagem de amostras de água das escolas públicas de Tangará da Serra/MT que atenderam e não atenderam a legislação vigente quanto a presença de coliformes totais nas duas coletas. Legenda: (1) coleta realizada em dezembro de 2014; (2) coleta realizada em outubro de 2015. 
Embora não haja contaminação por E. coli, as amostras de água de algumas escolas apresentam contaminação por coliformes totais (Tabela 2; Figura 1) e estão fora dos padrões exigidos a Portaria n. 2.914, de 12 de dezembro de 2011 do Ministério da Saúde, pois a mesma prevê na tabela de padrão microbiológico da água para consumo humano, ausência de coliformes totais em $100 \mathrm{~mL}$ de água. A presença de coliformes totais na água não significa necessariamente contaminação fecal, mas é considerado um importante indicador de falhas no processo de manipulação e de condições higiênico-sanitárias insatisfatórias, necessitando de cuidados com o armazenamento da água no estabelecimento (FRANCO \& LANDGRAF, 2003).

Diversas pesquisas sobre a qualidade da água no âmbito educacional, tanto em escolas e universidades têm demonstrado que há casos de contaminação da água com coliformes totais e termotolerantes. O descaso e negligência com a qualidade da água têm sido apontado na literatura através de pesquisas que demonstraram contaminação em bebedouros, desde estabelecimentos universitários até em escolas de educação infantil (ANTUNES et al., 2004; ZULPO et al., 2006; BARBOSA et al., 2009; DANTAS et al., 2010; SIQUEIRA et al., 2010; TRINDADE et al., 2015).

A contaminação da água por bactérias do grupo coliformes totais e termotolerantes é fator preocupante, uma vez que estas assumem importância na possibilidade da existência de micro-organismos patogênicos, responsáveis pela transmissão de doenças de veiculação hídrica, tais como cólera, disenteria e criptosporidiose (BENETI, 2011).

A contaminação das águas nas escolas de ensino básico requer maior atenção uma vez que, as crianças estão mais vulneráveis, pois recebem maior exposição em relação aos adultos, além de seus organismos estarem imaturos (WHO, 2005). As crianças respiram maior quantidade de ar, comem mais e bebem mais água do que os adultos e, por isso podem ser relativamente mais expostas a contaminação por peso corporal (CEC, 2015). Dessa forma se torna importante e necessário, o monitoramento constante da qualidade da água nas escolas, a fim de identificar e corrigir os possíveis pontos de contaminação, garantindo assim o cumprimento das normas de qualidade da água para consumo pelos alunos das escolas amostradas no município de Tangará da Serra/MT.

O uso de métodos rápidos para detecção de bactérias do grupo coliforme tem sido uma ótima alternativa para análise da qualidade da água. Marquezi, Gallo \& Dias (2010) observaram que, tanto a detecção de coliformes totais, quanto de $E$. coli, foram melhores pelo uso de métodos rápidos, devido a maior capacidade de recuperação e crescimento das células de coliformes desses métodos e por eles serem específicos para $E$. coli, enquanto que o método fermentação em tubos múltiplos não tem tal especificidade. Afirmam ainda que, tanto Kit Colilert $^{\circledR}$, quanto Kit Colitag ${ }^{\mathrm{TM}}$, são recomendáveis como substitutos do método fermentação em tubos múltiplos. Além disso, o método Colitag ${ }^{\mathrm{TM}}$ recupera as células danificadas pelo cloro, devido a presença de trimetilamina, um composto básico que neutraliza o pH baixo (US-EPA, 2004; OLSTADT et al., 2007). Uma das interferências do uso dos métodos rápidos está no fato de Enterobacteriaceae, incluindo bactérias dos gêneros Salmonella, Shigella, Citrobacter, Yersinia, também produzirem beta-glucoronidase, enzima utilizada para deteç̧ão de $E$. coli, podendo levar a um certo número de organismos de falsos-positivos. Entretanto, a literatura indica que essas interferências resultam em menores erros que os métodos tradicionais (KÖSTER et al., 2003). 


\section{CONCLUSÃO}

Diante dos resultados obtidos através das análises bacteriológicas, pode-se observar que, dentre as 14 escolas escolhidas, um total de 21,4\% das amostras não atende a um dos parâmetros bacteriológicos (ausência de coliformes totais) exigidos pela portaria n. 2.914, de 12 de dezembro de 2011 do Ministério da Saúde. Portanto, o resultado demonstra a necessidade de melhorar o monitoramento das caixas d'águas e bebedouros de algumas escolas, visando a concretização de medidas de controle de qualidade da água e de intervenção para garantir água potável a todos estudantes e evitar a transmissão de surtos de doenças de veiculação hídrica no ambiente escolar de Tangará da Serra/MT.

\section{REFERÊNCIAS BIBLIOGRÁFICAS}

Amaral, M. (2011) Análise microbiológica de caixas d'água de colégios estaduais de Foz do Iguaçu - Paraná. (Trabalho de Conclusão de Curso - Especialização) - Universidade Tecnológica Federal do Paraná - UTFPR, Foz do Iguaçu, PR, Brasil.

Antunes, C. A., Castro, M. C. F. M. \& Guarda, V. L. M. (2004) Influência da qualidade da água destinada ao consumo humano no estado nutricional de crianças com idades entre 3 e 6 anos, no município de Ouro Preto - MG. Alimentos e Nutrição, 15(3), 221-226.

Barbosa, D. A., Lage, M. M., Badaró, A. C. L. (2009). Qualidade microbiológica da água dos bebedouros de um campus universitário de Ipatinga, Minas Gerais. Nutrir Gerais, 3(5), 505517.

Beneti, A. D. (2011) Guidelines for drinking water quality. Revista Engenharia Sanitária e Ambiental, 16(4), 499-513.

Brasil. (2013) Fundação Nacional de Saúde. Manual prático de análise de água. (4a ed). Brasília: Funasa.

Brasil. (2014) Fundação Nacional de Saúde. Manual de controle da qualidade da água para técnicos que trabalham em ETAS. (1a ed) Brasília: Funasa.

Castro, A. S., Silva, B. M. \& Fabri, R. L. (2013) Avaliação da qualidade físico-química e microbiológica da água dos bebedouros de uma instituição de ensino superior de juiz de fora, Minas Gerais. Nutrir Gerais, 7(12), 984-998.

Commision for Environmental Cooperation (CEC). (2006) (Children's health and the environment in North America: a first report on available indicators and measures. p. 144. Disponível em: <http://www.cec.org/Storage/27/1799CEC_Children_and_Health_en .pdf> Acesso em: $10 \mathrm{de}$ nov. 2015.

Dantas, A. K. D., Souza, C., Ferreira, M. S., Andrade, M. A., Andrade, D. \& Watanabe, E. (2010) Qualidade microbiológica da água de bebedouros destinada ao consumo humano. Revista Biociências, 16(2), 132-138.

Fernandes, M. S. M. [Maniza], Alves, R. V., Costa, T. S. \& Franca, K. B. (2014) Avaliação da qualidade microbiológica da água disponibilizada em bebedouros de uma instituição de ensino superior. In: X Encontro Nacional de Águas Urbanas, 2014, São Paulo. X Encontro Nacional de Águas Urbanas.

Fernandes, L. L [Luana] \& Gois, R. V. (2015). Avaliação das principais metodologias aplicadas às análises microbiológicas de água para consumo humano voltadas para a detecção de coliformes totais e termotolerantes. Revista Científica da Faculdade de Educação e Meio Ambiente, 6(2), 49-64.

Franco, B. D. G. M. \& Landgraf, M. (2003) Microbiologia dos alimentos. Atheneu: São Paulo. 
Freitas, M. B. \& Freitas, C. M. A. (2005). Vigilância da qualidade da água para consumo humano desafios e perspectivas para o Sistema Único de Saúde. Ciência e saúde coletiva, 10(4), 9931004.

Hofstra, H. \& Veld, J. H. J. H. (1988). Methods for the detection and isolation of Escherichia coli including pathogenic strains. Journal of Applied Bacteriology, Symposium Supplement, 197S212S.

Koster, W, Eglil, T., Ashbolt, N., Botzenhart, K., Burliom, N.; Endo, T., Grimond, P., Guillot, E., Mabilat, C., Newport, L., Niemi, M., Payment, P., Prescott, A., Renaud, P. \& Rust, A. (2003). Analytical methods for microbiological water quality testing. In: Assessing microbial safety of drinking water. (pp. 237-292).London: OECD.

Marquezi, M. C.; Gallo, C. R.; \& Dias, C. T. S. (2010). Comparação entre métodos para a análise de coliformes totais e E. coli em amostras de agua. Revista do Instituto Adolfo Lutz, 69(3), 291296.

Olstadt, J.; Schauer, J. J.; Standridge, J. \& Kluender, S. (2007). A comparison of ten USEPA approved total coliform/E. coli tests. Journal of Water and Health, 5(2), 267-282.

Sá, L. L. C.; Jesus, I. M; Santos, E. C. O.; Vale, E. R.; Loureiro, E. C. B. \& Sá, E. V. (2005) Qualidade microbiológica da água para consumo humano em duas áreas contempladas com intervenções de saneamento - Belém do Pará, Brasil. Epidemiologia e Serviços de Saúde, 14 (3), 171-180.

Silva, N.; Junqueira, V. C. A.; Silveira, N. F. A.; Taniwaki, M. H. \& Santos, R. F. S. (2010). Manual de métodos de análise microbiológica de alimentos e água. (4a ed). São Paulo: Varela.

Siqueira, L. P.; Shinohara, N.K.S.; Lima, R.M.T.; Paiva, J.E.; Filho, J. L. L., \& Carvalho, I. T. (2010). Avaliação microbiológica da água de consumo empregada em unidades de alimentação. Ciência \& Saúde Coletiva, 15(1), 63-66.

Sperling, M. V. (2014). Introdução a qualidade das águas e ao tratamento de esgotos. (4a ed). UFMG: Belo Horizonte.

Trindade, G. A. DA; Sá-Oliveira, J. C. \& Silva, E. S. (2015). Avaliação da qualidade da água em três Escolas Públicas da Cidade de Macapá, Amapá. Biota Amazônia, 5(1), 116-122.

US Environmental Protection Agency (2004). Federal Register 40 CFR Part141, February 13(69), no 30 - Colitag ${ }^{\mathrm{TM}}$.

Zago, B. W., Carvalho, I. F. \& Carvalho, M. L. S. (2013) Qualidade bacteriológica de água mineral. Alimentos e Nutrição, 24 (3), 311-315.

Zulpo, D. L.; Peretti, J.; Ono, L. M. \& Garcia, J. L. (2006). Avaliação microbiológica da água consumida nos bebedouros da Universidade Estadual do Centro-Oeste, Guarapuava, Paraná, Brasil. Semina: Ciências Agrárias, 27(1), 107-110.

World Health Organization (WHO). (2005). Children's health and environment: developing action plans. 2005. Who Regional Office for Europe, Denmark. 